\title{
The Merit of a Municipal Service Review and the Potential Application for Southeastern Louisiana Water Suppliers
}

\author{
Jesse D. Noel, Syed Adeel Ahmed* \\ College of Engineering, University of New Orleans, United States
}

Copyright (C) 2015 Horizon Research Publishing All rights reserved.

\begin{abstract}
Municipal services are essential to the maintenance of a civil society. Without these services, clean water would not be available, sewerage would run through the streets, and transportation would be nonexistent. It is because of this that we should strive to improve these services whenever possible. Evaluating the current state of services is imperative to discovering potential efficiencies of scale that can result in better service. When multiple municipalities are operating similar facilities in relatively close proximity, it would behoove them to evaluate their systems and ensure that the most benefit is being generated for their constituents by operating an individual municipal facility. Because they draw from the same water source, Southeastern Louisiana municipalities providing water service are ripe for a Municipal Service Review to evaluate the potential benefit of a combined utility or the potential for shared best management practices.
\end{abstract}

Keywords Municipal Service Review, Public Utility, Southeast Louisiana Water Systems

\section{Introduction}

During the development of municipal water systems, geographic location and taxing structures as well as population affect the service area of any proposed system. These constraints make it logical for a single municipality to initiate a system and to operate and maintain that system for the benefit of the residences within that municipality. Many factors are considered when developing a water system other than those previously mentioned. These factors may include the raw water source such as a river or aquifer, the land available for a treatment facility and treated water storage, and the pumping capacity required to distribute the treated water to the residents of the municipality.

While each municipality faces its own unique design criteria for its treatment and distribution system, there are metropolitan areas that have utilized a combined water district to service multiple municipalities. One such district is the Metropolitan Water District (MWD) of Southern
California. This water district is "a consortium of 26 cities and water districts that provides drinking water to nearly 19 million people in parts of Los Angeles, Orange, San Diego, Riverside, San Bernardino and Ventura counties."1 This such system reduces redundancies in a geographic area that uses the same raw water source and has consistent distribution design standards. While the MWD now represents 26 entities, the process of convincing each entity to partake in the single source water system was a long and arduous task.

The New Orleans metro area consists of at least 5 parishes that rely on the Mississippi as raw water for their potable water system. The parishes in question are Plaquemines, St. Bernard, Orleans, Jefferson, and St. Charles. Currently each municipality operates an autonomous water treatment and distribution system serving only the members of their respective parish. Many studies have been conducted in other regions of the country and throughout the world to determine the potential benefits of combining resources across municipal lines to reduce costs and create efficiencies in the treatment and distribution processes. The many systems in the Metro area may benefit from a similar analysis to determine efficiencies and reduce costs across municipal lines.

\section{Analysis and Systems Summary}

A baseline for system comparison was developed in which Water Cost, Residents served and Production capacity were evaluated. This paper focused solely on water treatment and did not take into account distribution systems. These systems do require further evaluation in a potential full scale municipal service review to seek the full benefit of this assessment method.

Table 1 delineates the information found for each of the water systems in question. The table depicts the prices; residents served and water production capacity of each system to illustrate the disparity in the systems.

As seen in Table 1, the fees associated with the various water systems are disparate, but many factors contribute to this variation. Some of the factors include; distribution 
system maintenance and scale, intake and treatment system costs, system employee benefits and costs associated, and non-revenue water production.

Table 1. Cost/Production Comparison Chart

\begin{tabular}{|c|c|c|c|c|}
\hline \multicolumn{5}{|c|}{ Key Component Comparison by Parish } \\
\hline Parish & $\begin{array}{c}\text { Base } \\
\text { Price } \\
\text { Per } \\
1000 \\
\text { Gallons }\end{array}$ & $\begin{array}{c}\text { Secondary } \\
\text { Price Per } \\
1000 \\
\text { Gallons }\end{array}$ & $\begin{array}{c}\text { Residents } \\
\text { Served }\end{array}$ & $\begin{array}{c}\text { Production } \\
\text { Capacity }\end{array}$ \\
\hline $\begin{array}{c}\text { St Charles } \\
\text { (East Bank) }\end{array}$ & 2.64 & 4.77 & 29517 & 13 MGD \\
\hline $\begin{array}{c}\text { Jefferson } \\
\text { (East Bank }\end{array}$ & 2.81 & 1.98 & 243,782 & 87 MGD \\
\hline $\begin{array}{c}\text { Orleans } \\
\text { (East Bank) }\end{array}$ & 3.26 & 5.57 & 291,044 & 135 MGD \\
\hline St Bernard & 1.65 & -- & 44000 & 12 MGD \\
\hline $\begin{array}{c}\text { Plaquemines } \\
\text { (Belle } \\
\text { Chasse) }\end{array}$ & 2.8 & 2 & 17391 & 4MGD \\
\hline \multicolumn{5}{|c|}{ Base Price Quantity varies by jurisdiction. } \\
\hline
\end{tabular}

Water cost should be borne by the user and not the public at large. It is important that the rates charged properly account for current system operation as well as indefinite maintenance and upgrades as applicable. The existing rates show no correlation between production capacity and citizens served. The geography may play a greater role in rates due to distribution concerns. Further evaluation in the form of a full Municipal Service review may be warranted based on this data. Case studies in municipal system analysis are detailed below that demonstrate approaches that may be considered when conducting the comprehensive review.

\section{Athens, Vils and the GNO}

Stefanos Xenarios evaluated the Athens and Vils wastewater systems in his paper "Developing an ecological-economic assessment framework for urban wastewater systems: the case of Athens and Vils wastewater systems." In this article Xenarios presents a framework to assess the benefits of improving the ecology of a system and the cost benefits associated with the improvements. $\mathrm{He}$ first studied the receiving waters of the treatment systems to determine the existing ecological situation and then polled various stakeholders as to the costs and benefits of improving the systems. Vils was found to be in exceptional shape while Athens warranted some improvements, but neither of the economic assessments justified substantial investment into the wastewater infrastructure based on the European Water Framework Directive.

The Greater New Orleans area could benefit from similar studies involving both its water and wastewater systems. The ecology of the receiving water which is the Mississippi River is such that no large impact will be realized by altering any of the systems in question. Although this may be the case, polling stakeholders including local experts, officials, and operators to evaluate each of the systems and their respective strengths and weaknesses may be a good place to begin a deep analysis of the systems and how they are intertwined.

\section{Combined Versus Individual Facilities}

"Economic evaluation of combined treatment for sludge from drinking water and sewage treatment plants in Japan" evaluates the advantages of investing in an individual water sludge treatment plant vs using a combined water treatment sludge and wastewater treatment sludge processing plant. The aging infrastructure in Japan and the need for optimized rehabilitation led to the study. The authors evaluated the prospective costs of development and operation of the two alternatives to better understand the alternatives available and any potential benefits associated with them.

The conclusion in this particular scenario point to the beneficial use of a combined sewer sludge treatment and water sludge treatment facility which utilizes a sludge pipeline to transport the water treatment sludge to the wastewater sludge treatment facility would be most beneficial. The reduced operating costs and costs associated with a new water sludge treatment plant lead to this conclusion.

The idea of combining existing systems as seen in this evaluation is pertinent to the GNO area as the infrastructure is aging throughout. Many facilities require rehabilitation and many more will eventually require replacement. The potential to combine facilities within a parish should most definitely be evaluated, but the prospect of evaluating a regional system cannot be ignored. The potential gains in efficiency for each parish should they decide to combine resources should be investigated to best steward the public's interest.

\section{Municipal Service Review}

Contra Costa County in California commissioned a Municipal Service Review and Sphere of influence study to evaluate the disparate systems located within their county as mandated by the State of California. This study evaluated the 8 cities, 21 special districts and 1 private water company operating within the county. The water services were evaluated for:

"1. Growth and population projections for the affected area.

2. The location and characteristics of any disadvantaged unincorporated communities within or contiguous to the sphere of influence.

3. Present and planned capacity of public facilities, adequacy of public services, and infrastructure needs or 
deficiencies including needs or deficiencies related to sewers, municipal and industrial water, and structural fire protection in any disadvantaged, unincorporated communities within or contiguous to the sphere of influence.

4. Financial ability of agencies to provide services.

5. Status of, and opportunities for, shared facilities.

6. Accountability for community service needs, including governmental structure and operational efficiencies.

7. Any other matter related to effective or efficient service delivery, as required by commission policy. “

This review framework is state law in California and mandated to be performed by each Local Agency Formation Commission to ensure adequate public services are maintained and to ensure resources are best utilized. Louisiana's public infrastructure has no such mandate through state law, but never the less could benefit from a full Municipal Service Review. The region known as the Greater New Orleans Area (GNO) as stated previously contains 5 parishes that currently operate autonomously which ensures that there are efficiencies being lost in the public utilities. The community as a whole could benefit from the pooling of resources to enable fiscal responsibility by all parties involved to ensure that top level services are offered for the most affordable price.

\section{Multiple indicator Approach}

Swindle and Kelly evaluated data collection methods for multiple indicators of public service satisfaction. Through this analysis they found that "Public management would be served by developing better, multiple measures to gauge government service effectiveness that include citizen surveys." Context must be given to the survey questions to ensure adequate data interpretation, and determine correlation to administrative evaluation tools being used to guide the service in question.

Including a human element into a Greater New Orleans municipal service review will ensure that any proposed improvement will not infringe on a particular portion of the community some service change they do not desire. It will also enable engagement which has been shown to improve customer satisfaction regardless of the level of service as measured by administrative evaluation techniques.

Any survey administered to provide input to the MSR should be evaluated at the neighborhood level as service disparities may currently exist that would need to be accounted for in a system master plan. A great disparity in customer satisfaction is anticipated due to the geographical distribution limitations and aging infrastructure currently in place.

\section{Public utilities and the Free Market}

"Budget-maximizing bureaucrats and restrictive labor contracts may prevent exploration of privatization and cooperation (Savas2000)". Internal opposition from elected officials, line employees, department heads, and restrictive labor agreements is a substantial impediment to combining municipal services.

In order to provide an adequate evaluation through a MSR, one "must elaborate new theories of local government that give attention not only to efficiency, equity, and democracy but also to community."(WARNER and HEFETZ 2002) The political and socio-economic structure of the GNO is such that crossing boundaries must be done with care and must prove beneficial to all parties involved.

As detailed in Warner and Hefetz's analysis, municipal cooperation is the method most likely to benefit some municipalities in the metro area. Privatization has been shown to benefit efficiencies at the outset of the contract but with oversight requirements and changing community needs, this method is less likely to result in a positive outcome when considering the aforementioned socio-economic considerations.

While municipalities at the county level are likely to benefit from economies of scale and be less inclined to resort to municipal cooperation, it does not relieve them of the responsibility to provide the most effective service to their residents. Thus any municipal manager would be prudent to investigate all options available to improve both their service and that of the region of which they are a part.

\section{Water Distribution and purification System}

The main functions of water distribution and storage are: to permit continuous water treatment, uniform pumping rates of water into the distribution system, pressure stabilization, and reserve supply available for contingencies. Storage capacity considered to be available for firefighting is only the normal minimum daily amount of water maintained in storage.

From water purification point of view, Ozonation does not produce a disinfecting residual; therefore, chlorine is added to treated potable water before distribution to establish a disinfecting residual. Post chlorination is for disinfection of remaining pathogens and to establish a chlorine residual in the distribution system. One of the problems is that during the period of peak hourly flow, some customers living in the area where the water enters the distribution system are likely to complain of excess chlorine odor in the water. Manganese not taken out by the aeration-filtration process pass into the distribution system and the manganese in the treated water used in the solution-feed chlorinator can precipitate in the injector mechanism (Hammer, 2011).

Chlorine used in chlorination is both an oxidant and disinfectant. Chlorine is oxidizing the iron and manganese forming precipitates that settle out in the distribution system. Periodically these are flushed out of the mains and storage tanks to cause "rusty" water that result in staining. 
Apparently prior to chlorination most of the iron and manganese remained in solution and colloidal suspension and passed through the system unnoticed. Fluoride compound is added to restore the concentration to the optimum level, and chlorine is added to establish an adequate protective residual in the distribution system. (Hammer, 2011).

Cross connection control is important to prevent contamination of potable water in the distribution pipe network. Back siphonage is backflow resulting from reduced pressure in the potable system or excessive pressure from a source contaminated with chemicals or pathogens. From a disposal perspective, wastewater is something to be discharged and must meet water quality requirements for discharge or application requirements for reuse. The decision to reuse is based on the cost difference between treatment for a surface water discharge and treatment and distribution costs for recycling.

\section{Conclusions}

The water systems in the GNO are aging and in need of maintenance, rehabilitation and/or replacement in some instances. Evaluating the resources associated with each system as well as the potential for pooling those resources may allow for a more efficient system for all involved. A full system analysis should incorporate all of the methods used in the articles cited. This includes polling all relevant parties for their input into the relevance of system operating parameters, evaluating the combining of facilities within each parish to increase efficiencies, and completing a full review of how the individual systems work in aggregate, that is with respect to each other. While the water systems are the focus of this paper, this methodology can be extrapolated to include all municipal water and wastewater services.

Getting the stakeholders on board should be the first objective, as their participation is paramount to the effective completion of the study. The potential benefits from the analysis such as shared best management practices and efficient operating techniques amongst stakeholders should encourage participation. Once the stakeholders are on board, polling for system data such as treatment and distribution system layouts and designs, service and maintenance requirements, and administrative systems used will provide basis to begin the analysis.

Categorizing the costs associated with each system including operation costs, compliance costs, and administrative costs would then provide a basis for system comparison. Should these costs be similar, it may lend to the individual operation of each system as the connection distances may be too great to overcome the operating costs if all systems are operating similarly. More likely, efficiencies in each system will lend toward the sharing of BMPs and operating techniques that may also trump the prospect of connecting the systems. Should one system's operating efficiencies be substantially greater than the others in question, the prospect of utilizing that system as a supply source for the other systems should be assessed.

Ultimately, the municipal systems in place could benefit from partnering with their neighboring parishes to evaluate the aggregate system to ensure that the best production and distribution methods and processes are being utilized throughout the metro area to ensure the residents are being effectively served. Performing the analysis as discussed could lead to a more efficient and effective municipal service system for the Greater New Orleans Area.

\section{REFERENCES}

[1] Kelly, Janet M, Swindell, David,(2002) A Multiple-Indicator Approach to Municipal Service Evaluation: Correlating Performance Measurement and Citizen Satisfaction across Jurisdictions, Public Administration Review. Sep/Oct2002, Vol. 62 Issue 5,p610-621. 12p. 6 Charts

[2] Mildred Warner, Amir Hefetz(2002) Applying Market Solutions to Public Services: An Assessment of Efficiency, Equity, and Voice, Urban Affairs Review 2002 38: 70, http://uar.sagepub.com/content/38/1/70

[3] Tomoaki Miyanoshita, Naoki Oda, No Hayashi, Masahiro Fujiwaraand Hiroaki Furumai(2009) Economic evaluation of combined treatment for sludge from drinking water and sewage treatment plants in Japan, Journal of Water Supply: Research and Technology-AQUA, 58.3, p. 221-227

[4] Stefanos Xenarios(2008) Developing an ecological-economic assessment framework for urban wastewater systems: the case of Athens and Vils wastewater systems, Urban Water Journal, Vol. 6, No. 2, June 2009, $147-167$

[5] GST Consulting(2014) Combined Municipal Service Review and Sphere of Influence Study (2nd Round), Contra County Water and Wastewater Agencies, http://www.santaclaralafco.org/studies-service-reviews

[6] Savas, E. S. 2000. Privatization and public private partnerships. Chatham, NY: Chatham House.

[7] http://www.mwdh2o.com/mwdh2o/pages/about/about01.htm 1

[8] http://jp-appserver.jeffparish.net/waterbill/UtilityRates.htm

[9] https://www.swbno.org/custserv_information_rates_water.as $\mathrm{p}$

[10] http://www.stcharlesgov.net/index.aspx?page $=228$

[11] http://www.louisianaspeaks-parishplans.org/SecureSite/Vie w_LTRForm1.cfm?ProjID $=1260$

[12] "Water and Wastewater Technology", $7^{\text {th }}$ Seventh Edition by Mark J. Hammer \& Mark J. Hammer Jr. (2011) 